\title{
MODELLING AND VISUALIZING KNOWLEDGE ON THE REFERENCE SYSTEM AND VARIATIONS BASED ON THE MODEL OF PGE - PRODUCT GENERATION ENGINEERING FOR DECISION SUPPORT
}

\author{
Pfaff, Felix; \\ Rapp, Simon; \\ Albers, Albert \\ Karlsruhe Institute of Technology (KIT)
}

\begin{abstract}
In 2019, Dyson had to cancel its ambitious electric car project after having already 500 Million pounds spent. This example shows how difficult it is to assess the consequences of decisions on development targets as cost, risk, and innovation potential. Knowledge about references, variation types and their impact on development targets can help to increase the maturity of the decision basis. The model of PGE - product generation engineering describes these interrelations using the reference system. This contribution deals with the question of how knowledge about the impact of variation types and characteristics of reference system elements on new product generations can be made usable through modelling and visualization. Therefore, characteristics of reference system elements and their impacts on common development targets are collected through literature research. To process this knowledge base in technical information systems, an Entity-Relationship data model is developed. Through the implementation of a VR visualization, the data model is validated and a first visualisation approach is shown. The findings of this work can be used to systematise research on impact factors in PGE and to develop further digital methods.
\end{abstract}

Keywords: Design theory, Knowledge management, Design management

Contact:

Pfaff, Felix

Karlsruhe Institute of Technology (KIT)

IPEK Institute of Product Engineering

Germany

felix.pfaff@kit.edu

Cite this article: Pfaff, F., Rapp, S., Albers, A. (2021) 'Modelling and Visualizing Knowledge on the Reference System and Variations Based on the Model of PGE - Product Generation Engineering for Decision Support', in Proceedings of the International Conference on Engineering Design (ICED21), Gothenburg, Sweden, 16-20 August 2021. DOI:10.1017/ pds. 2021.478 


\section{INTRODUCTION}

In 2018, the vacuum cleaner manufacturer Dyson surprised experts with the announcement of its luxury electric vehicle N526 and ambitious target values as $0-100 \mathrm{~km} / \mathrm{h}$ in 5 seconds achieved by 2 electric motors providing $500 \mathrm{HP}$ and a range of $950 \mathrm{~km}$. In late 2019, the project was cancelled due to an uncompetitive target selling price of around $£ 150,000$ and 500 Million pounds already spent. (Times, 2020) In this case, the reference technologies were known but came from other branches and should even be superior to the state of the art in their performance, which ultimately led to uncontrollable costs and risks in the development process. This example shows how difficult it is, even for experienced companies, to correctly assess the consequences of decisions on development targets as cost, risk, and innovation potential in a complex development environment. Particularly the deciding between different solution alternatives is one of the basic tasks of developers in the product development process (Cross, 2008 , p. 151). It is the responsibility of the developer to make decisions under various boundary conditions and uncertainties. However, especially in the early phase of product development projects, the degree of maturity of the decision basis is low and uncertainty is high (Albers et al., 2017b). It is difficult to assess the impact of a decision, which can lead to decision aversion among decision-makers and delays in the project (Ehrlenspiel and Meerkamm, 2017, p. 232). Knowledge is of crucial importance for decision-making. Knowledge about references, variation types and their impact on development targets can help to increase the maturity of the decision basis and thus lead to better decisions. The Model of PGE - Product Generation Engineering describes these interrelations and has the potential to make them applicable in the development process (Albers et al., 2017b).

In this contribution, knowledge on the impact of references and variation types in the model of PGE was collected and modelled using the Entity-Relationship approach (Chen, 1976). Building on this systematized knowledge base, a virtual reality visualization was developed to support the developer in decision situations with context-specific knowledge.

\section{STATE OF THE ART}

\subsection{Evaluation as a basis for Decision Making in Product Development}

Every rational decision is preceded by an evaluation. An evaluation is based on evaluation criteria that are derived from the requirements of the technical system and on which the suitability of the alternative solutions can be measured. In product development, the "magic triangle" can be used for generally applicable criteria which at the same time represent important development targets: Quality, costs, time. (Ehrlenspiel and Meerkamm, 2017, p. 635)

Olesen et al. (1996) extend these universal criteria to include risk and environmental effects or sustainability. To directly apply time as a criterion for a decision presupposes that the exact impact of the alternative solutions on the project plan is known. For an initial assessment, activities resulting from a decision can be considered. New product generations often claim to be "innovative". One criterion for assessing the possibility of a product to become an innovation in the sense of the innovation definition according to Schumpeter (1934) can be its innovation potential. According to Albers et al. (2018), the three elements product profile (defines the initial system of objectives based on customer-, user-, and provider-benefit), invention and successful market launch must be sufficiently fulfilled for high innovation potential.

Breiing and Knosala (1997) state that evaluation methods for the selection between solution alternatives are principally similar (Figure 1).

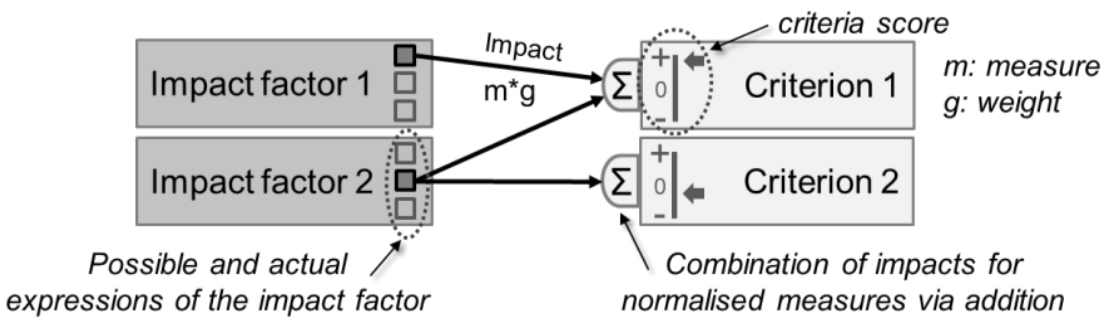

Figure 1: Evaluation model according to Breiing and Knosala (1997) 
Basis for the evaluation are explicit solution alternatives in a comparable form and their properties, which in this model represent the impact factors on the evaluation criteria. The expression of the impact factor of a solution alternative has an impact on the value of the respective evaluation criterion via the measure $m$ derived from it and the weight $g$ of the impact factor (see Figure 1). For normalised measurement numbers, the individual impacts $m * g$ are added to the criteria score.

\subsection{Approaches to describing the reuse of Knowledge in Product Development}

In Design Research there are various approaches existing whose aim is the reuse of knowledge from previous product development activities and other references such as predecessor or competitive products.

Design Reuse is a process of reusing existing design artefacts in new designs (Alblas and Jayaram, 2015). According to Shahin et al. (1999), much of the knowledge of developers and companies is contained in past products and shall therefore be stored in Design Reuse Systems which require the compatibility of the stored product models and the product model under development.

The overall objective of Engineering Change Management is to increase design flexibility by minimizing the impact of engineering changes. Associated with this is the minimization of direct negative effects on time, cost and quality of engineering changes, the propagation of engineering changes (change propagation) and resulting process changes. (Alblas and Jayaram, 2015)

The C-K theory is described by Hatchuel and Weil (2003) as "unified design theory" where the existing knowledge of the developer is modelled in the "Knowledge-Space" (K-Space) in which all possible elements of knowledge can be stored.

According to Albers et al. (2015), the model of PGE is "a new descriptive model [...] that describes product development from the new perspective of product generation development". The model of PGE is based on two fundamental hypotheses (Albers et al., 2019b; Albers et al., 2020; Albers et al., 2015):

- Each product is developed based on a reference system $R_{\mathrm{n}}$ (Figure 2, left). Elements of the reference system $(R S E)$ originate from existing or already planned socio-technical systems and the associated documentation and serve as a basis and starting point for the development of a new product generation $G_{\mathrm{n}}$.

- The subsystems of a new product are developed based on reference system elements exclusively by three types of variation: During the carryover variation of a subsystem (CV), the corresponding reference system element is carried over and is, if necessary, only adjusted at the interfaces during the system integration. Variation of attributes (AV) is the new development of a subsystem while retaining the solution principle of the reference system element and changing function-determining attributes. In the new development by principle variation (PV), the function of the reference system element is fulfilled by an alternative solution principle.

When planning new product generations, the question arises, what impacts the reference system and the variation types have on the development targets of the $G_{\mathrm{n}}$. To this end, the impact of the type of variation and the origin of $R S E$ of a subsystem on the criterion risk of the subsystem has been examined and visualized in the PGE risk portfolio (Albers et al., 2017b).
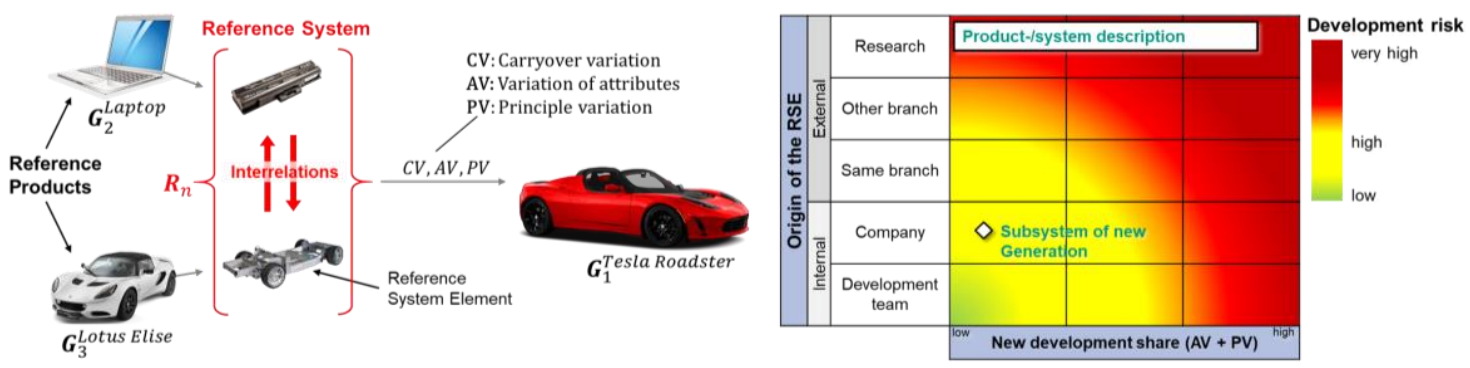

Figure 2: On the left: The reference system in the model of PGE (Albers et al., 2019b); On the right: PGE risk-portfolio (Albers et al. 2017b)

\subsection{Data, Information, and Knowledge Modelling}

The awareness of the importance of knowledge and the management of knowledge in companies is increasing (Takeuchi and Nonaka, 2012, p. 121). The goal of knowledge management is the structured collection and transfer of knowledge (North, 2016, p. 3). Takeuchi and Nonaka divide knowledge into explicit and implicit knowledge. "Explicit knowledge can be expressed in words and numbers and can 
be easily communicated through data, scientific formulas, established procedures or universal principles" (Takeuchi and Nonaka, 2012, p. 23). Thus, explicit knowledge in the form of data and information can be stored in databases (North, 2016, p. 37).

Implicit knowledge is subject-related and deeply linked to the experiences and activities of the individual and cannot be stored in databases. For the transmission of implicit knowledge, a process of transformation of implicit into explicit knowledge is necessary. (Takeuchi and Nonaka, 2012, p. 24)

Through the process of data modelling data gets structure. Data models lay the foundation for the development of information systems (Gadatsch, 2019, p. 4). The main advantage of abstract data models is their independence from database systems or programming languages which predestines them for design theoretical research. A proven data model is the Entity-Relationship Model (ERM) according to Chen (1976), which is based on three elements to describe data:

- Entity types represent aspects from the real world on an abstract level and are the objects of interest in visualizations. Entities can, for example, be individual stakeholders or technical (sub)systems.

- Relationship types describe the relationship between entity types. These can be relationships of any kind (physical, structural, causal, temporal etc.)

- Attributes can be assigned to both entity types and relationship types and describe them in more detail. For example, the properties of entities can be described as attributes. Attributes of a specific entity or relationship have attribute values as their characteristic values.

\subsection{Information and Knowledge Visualization}

According to Card et al., the visualization of information in the context of computer-generated visualizations is the "interactive, visual representation of abstract data to enhance cognition" (Card et al., 1999, p. 6). The purpose of visualizations is a deeper insight, not the creation of images for their own sake. The goal is to support decision making and explanation. Visualization is therefore useful if it supports people in these and other cognitive activities. (Card et al., 1999).

To get from structured data to visual elements, visual mapping by graphic engines and their algorithms is necessary. What the user finally sees on the screen is generated and manipulated by view transformations. (Ware, 2013)

Visualizations benefit from high-quality presentation and interactive manipulation of these presentations by the user (Card et al., 1999, p. 6). Virtual Reality (VR) offers the potential to simplify the handling of complex information and knowledge spaces through viewer-dependent immersive presentation and a particularly natural and intuitive interaction (Dörner et al., 2019, p. 15). In product development, VR and Augmented Reality (AR) are for example used for product validation, especially in early phases of the product development process (Reinemann et al., 2018).

\section{AIM OF RESEARCH AND RESEARCH APPROACH}

The overall aim of this research is to support the developer in the decision-making process in product development. For this purpose, it was investigated based on the model of PGE how knowledge about the impact of variation types and the impact of characteristics of the $R S E$ on the $G_{\mathrm{n}}$ can be made usable through modelling and visualization. Building upon the PGE Risk-Portfolio (Figure 2, right) and the evaluation model of Breiing and Knosala (Figure 1), this work aims at identifying further characteristics of $R S E$ as impact factors and evaluating their effects on the criteria cost, risk, innovation potential, activities, quality and sustainability. To achieve this aim, the following research questions had to be answered:

- Which characteristics of $R S E$ are impact factors and what is their impact on the criteria cost, risk, innovation potential, activities, quality and sustainability?

- How can the knowledge of impact factors in the model of PGE and their impact on the criteria be modelled for processing in technical information systems?

- How suitable is the developed model for the implementation of technical information systems respecting applicability and usefulness?

- How can the knowledge be visualied to support decision making in product development?

To answer the first question, the evaluation model of Breiing and Knosala was applied to the impact of influencing factors from the reference system on the evaluation criteria of the $G_{\mathrm{n}}$. This model was used to collect impact factors and their effects on the evaluation criteria through literature analysis (section 4). To process this knowledge base in technical information systems, an ERM-data model was developed 
(section 5). To answer the third and fourth research question, an exemplary visualization approach was implemented (section 6) and the applicability and usefulness of the data model were initially evaluated.

\section{IMPACT OF VARIATIONS AND CHARACTERISTICS OF RSE ON GENERAL EVALUATION CRITERIA}

By including the characteristic origin of the RSE and the type of variation as impact factors in the risk evaluation of the $G_{\mathrm{n}}$ subsystems, previously unavailable knowledge is brought into the evaluation process. This relationship was modelled and has the potential of integrating further criteria and impact factors (Figure 3).

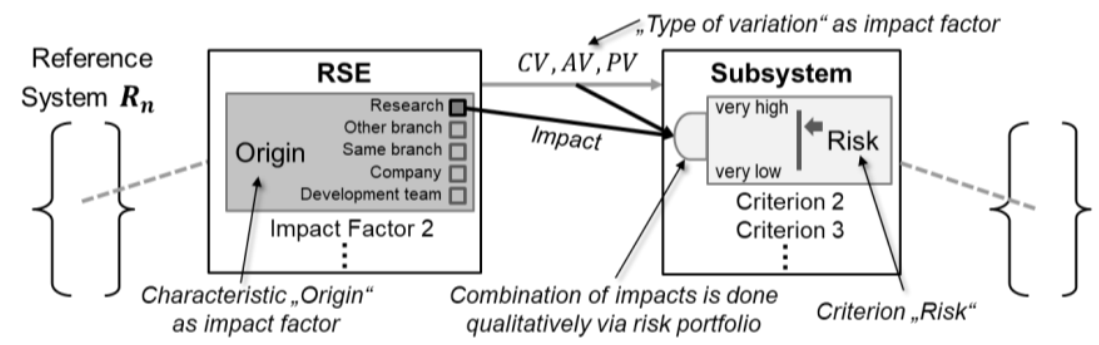

Figure 3: Relationship between type of variation, origin and risk for the PGE risk portfolio integrated into the evaluation model of Breiing and Knosala

$R S E$ are elements from socio-technical systems (Albers et al., 2019b). Therefore, RSE can have all the characteristics of elements from socio-technical systems. Through literature analysis, important characteristics of reference system elements as potential impact factors on common development targets as evaluation criteria were collected: The origin, complexity and maturity level of $R S E$. The impact tendencies of these impact factors on the criteria were qualitatively rated from very negative ($-)$ to very positive $(++)$, depending on their expression. Table 1 provides an overview. The result reflects the current state of research but does not claim to be complete.

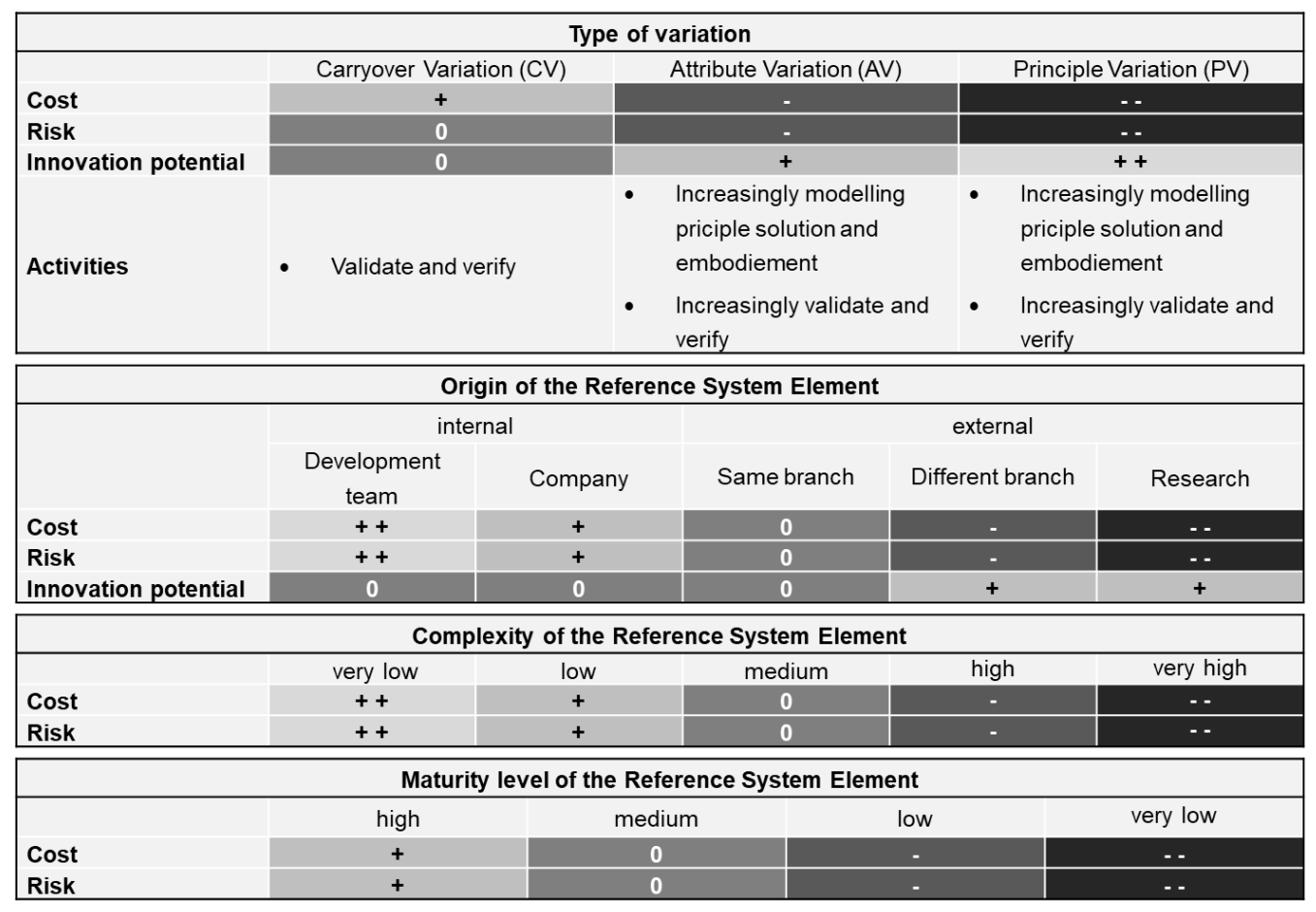

Table 1: Impact factors. Type of variation: Albers et al., 2017b; Albers et al., 2017a; Albers et al., 2019a; Bailom et al., 1996; Albers et al., 2014; Heismann and Maul, 2012, p. 41;

Origin of the RSE: Albers et al., 2017b; Complexity of the RSE: Hubka, 1984, p. 87;

Ehrlenspiel et al., 2014, p. 154; Wißler, 2006, p. 25; Maturity level of the RSE: Ehrlenspiel and Meerkamm, 2017, p. 49

From the literature research on the impact factors and the analysis of the impacts on the evaluation criteria of the $G_{\mathrm{n}}$, mainly impacts on cost and risk could be identified. For instance, increasing 
complexity leads to increased development costs, as the complexity of the element correlates with the complexity of the task (Hubka, 1984, p. 87). This makes analysis and synthesis activities that start from more complex reference system elements more expensive. Also, complexity in the product development process increases the technical risk (Wißler, 2006, p. 25). Thus, a complex RSE increases the risk in the product development process. A direct influence of the characteristics of $R S E$ on sustainability and quality could not be identified. These two criteria may depend strongly on the final implementation or construction of the technical system and thus indirectly on the type of variation. In the first step, only direct influences were considered. Activities as a consequence of the characteristics of $R S E$, in contrast to activities as a consequence of variations, have not yet been investigated.

\section{MODELLING KNOWLEDGE ABOUT THE IMPACT OF VARIATIONS AND REFERENCE SYSTEM ELEMENTS IN THE MODEL OF PGE}

From the evaluation model in Figure 3, the following Entities were identified: The reference System (Entity $R_{\mathrm{n}}$ ), the elements of the reference System (Entity RSE), the new product generation under development (Entity $G_{\mathrm{n}}$ ) and the subsystems of the product generation under development (Entity SubSys).

For identification purpose, all entities were given an identifier as a key attribute. The hierarchical concept (super-/subsystem character) according to Ropohl (2009) of SubSys and RSE entities to their corresponding $G_{\mathrm{n}}$ respectively $R_{\mathrm{n}}$ were modelled by the relationship consists of. At this point, two simplifying adoptions were made to facilitate the prototypical implementation: The interrelationships of the RSE among each other and the hierarchical character of the subsystems among each other were not taken into account. As a result of this simplification, there was only one system level to be considered for implementation.

The characteristics of the reference system elements could be understood as attributes of the entity $R S E$ or the evaluation criteria as attributes of the entity SubSys. However, since the effects of the characteristics on the criteria and thus the relationship "characteristics as impact factors have an impact on criteria" was to be modelled, characteristics of RSE which are impact factors and evaluation criteria also had to be entity types. In addition to their identifiers, the entity characteristics has the expression as a further attribute (e.g. characteristic "origin" with the expression "internal, company"). The entity evaluation criteria has the score of the criterion as a further attribute. The evaluation criteria in this model are linked to the subsystems SubSys, thus the evaluation of the impact on the criteria is carried out at the subsystem level. The essential variation concept of the model of PGE was modelled by the variation relationship between RSE and SubSys with the attribute variation type which can have the values $C V, A V$ and $P V$. To enable traceability of the variation relationships, it also carries an identifier. Several RSE can be assigned to one SubSys via variation relationships and vice versa several SubSys to one RSE. So theoretically, the variation relationship is of N...N cardinality. In this case, further simplification was made for easier implementation and the cardinality of the variation relationship was reduced to $1 \ldots$ N. Therefore, every SubSys can only be related to one $R S E$ in this model. Figure 4 shows the resulting Entity-Relationship Model with simplifications marked.

The data model is divided into two parts: The upper part represents the database which contains information about the system structure of the generation under development $G_{\mathrm{n}}$, the corresponding reference system $R_{\mathrm{n}}$, and the linking variation relationships. All this information can be provided through systems modelling in the development process if the model of PGE is integrated as a fundamental concept. So the database is specific for the system under investigation which in the context of decision making is the alternative solution for the $G_{n}$ to be evaluated.

The lower part represents the knowledge base with knowledge about the impact of the characteristics of $R S E$ and the type of variation on the evaluation criteria of the $\mathrm{G}_{\mathrm{n}}$ encoded in data. This knowledge is independent of the system under investigation and has to be interpreted for every specific system information dataset (upper part). 


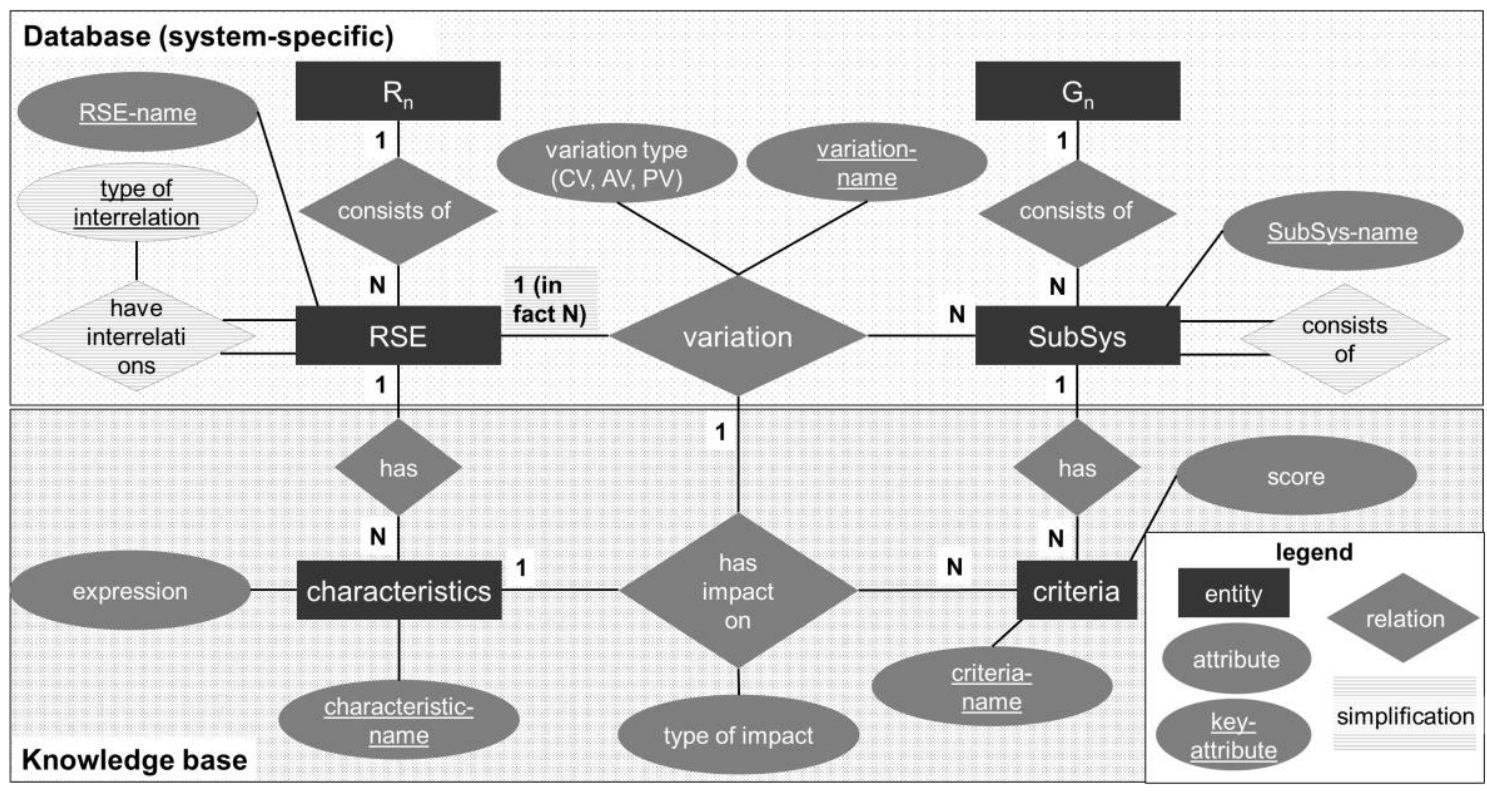

Figure 4: Entity-relationship model of the impact of the characteristics of RSE and the type of variation on the evaluation criteria of the $G_{n}$

For a computer-generated visualization, the interpretation of the knowledge base specific for the system under investigation has to be automated. The aim is to calculate values for the evaluation criteria representing the cumulated impact of the variation relationship and the characteristics of the $R S E$ for every subsystem SubSys. The ERM data model is not sufficient here and has to be supplemented with a mathematical model.

To represent the qualitative impacts from section 4, a numeric scale from 1 to 5 (wherein Table 1 "---" corresponds to 1 and " ++ " to 5) is chosen for the measure $m$ of the impact of one impact factor (see Figure 1). The weight $g_{\mathrm{k}}$ of every impact factor is equally set to the value $1 / n$ which leads to the ordinary arithmetic mean (Figure 5 right). The determination of weights requires prioritization between the impact factors which will be the topic of future work. The assignment of the mean impact values to the criteria score is carried out via a step function with equidistant intervals (Figure 5, left) where every value between 1 and 5 again corresponds to a linguistic evaluation from very negative to very positive.

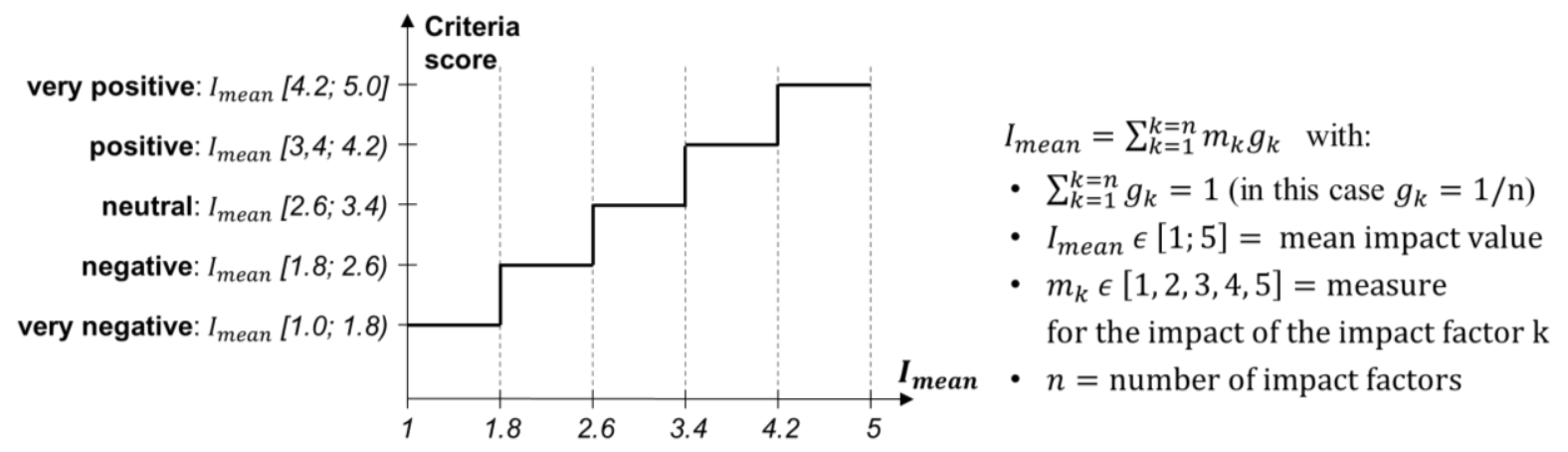

Figure 5: Mathematical model for evaluating the score of each criterion

The assumptions made for the mathematical correlations for calculating the impact of the expression of the characteristics and the type of variation as impact factors on the evaluation criteria are the simplest possible correlations. The mathematical model is capable of including quantitative correlations through the adaption of the weights or the intervals of the step function but these relationships have not been quantitatively researched yet.

\section{VIRTUAL REALITY KNOWLEDGE ROOM AS AN EXAMPLE OF A VISUALIZATION APPLICATION}

With the increasing complexity of the evaluation due to the additional evaluation criteria and impact factors considered, the portfolio visualization approach of Albers et al. (2017b) must be extended. To 
deal with this complexity, a VR-Visualization approach was chosen because of the potentials of the technology described above.

The abstract functionality of the visualization application is to automatically evaluate product-related data with the knowledge base, clearly illustrate the results at first and to call up detailed information as required. Following Shneiderman's mantra of information visualization - „overview first, zoom and filter, then details on-demand" (Shneiderman, 1996, p. 336) - the functionality of the application is representative for data-based knowledge visualization. Thus, the applicability and usefulness of the proposed knowledge model for implementing such systems can be validated. As software development framework the Unity 3D engine with the Vuforia SDK was chosen. Based on the following fictive development scenario a mock-up was created: "A bicycle manufacturer wants to develop an e-scooter $\left(G_{\mathrm{n}}\right)$ that will offer superior comfort and driving characteristics compared to competing products. For this purpose, RSE from other development teams (origin: internal, company) and competitors in the bicycle industry (origin: external, same branch) are the basis for the development of the subsystems of the chassis, brake and drive components of the e-scooter."

\subsection{Implementation of the automated evaluation}

The knowledge base is implemented by JSON files, which represent Table 1 with impact tendencies from Section 4 in a readable form for higher programming languages. JSON is a standardised data exchange format which can be easily edited from and exchanged with other programs like database management systems or CAx programs. Each factor is given a JSON file in which the impacts on the evaluation criteria are stored both numerically, corresponding to the mathematical model in Figure 4, and in natural language by a string with the reason for the impact.

The information specific for the system under development has to be modelled via predefined SubSys, variation and RSE objects. The SubSys objects carry the evaluation criteria and the RSE objects carry the characteristics of the RSE. Both are connected to the corresponding 3D data of the $G_{\mathrm{n}}$ and the $R_{\mathrm{n}}$. The objects for the variation relationships carry the references of the RSE and SubSys they connect.

The algorithmic implementation of the impact-evaluation based on the mathematical model is done in C\#. Via the variation relationship, the RSE assigned to the respective SubSys is found. For each impact factor, the correct entry in the associated JSON is found via the expression of the characteristics and the variation type and written into an array. After this query, there is an array for each SubSys, which contains the relevant information collected from the JSONs. For the calculation of the mean impact value, the corresponding values from the array are collected. Then the scores of the evaluation criteria are determined using a case distinction via the step function.

\subsection{Visualization of the evaluation results in Virtual Reality}

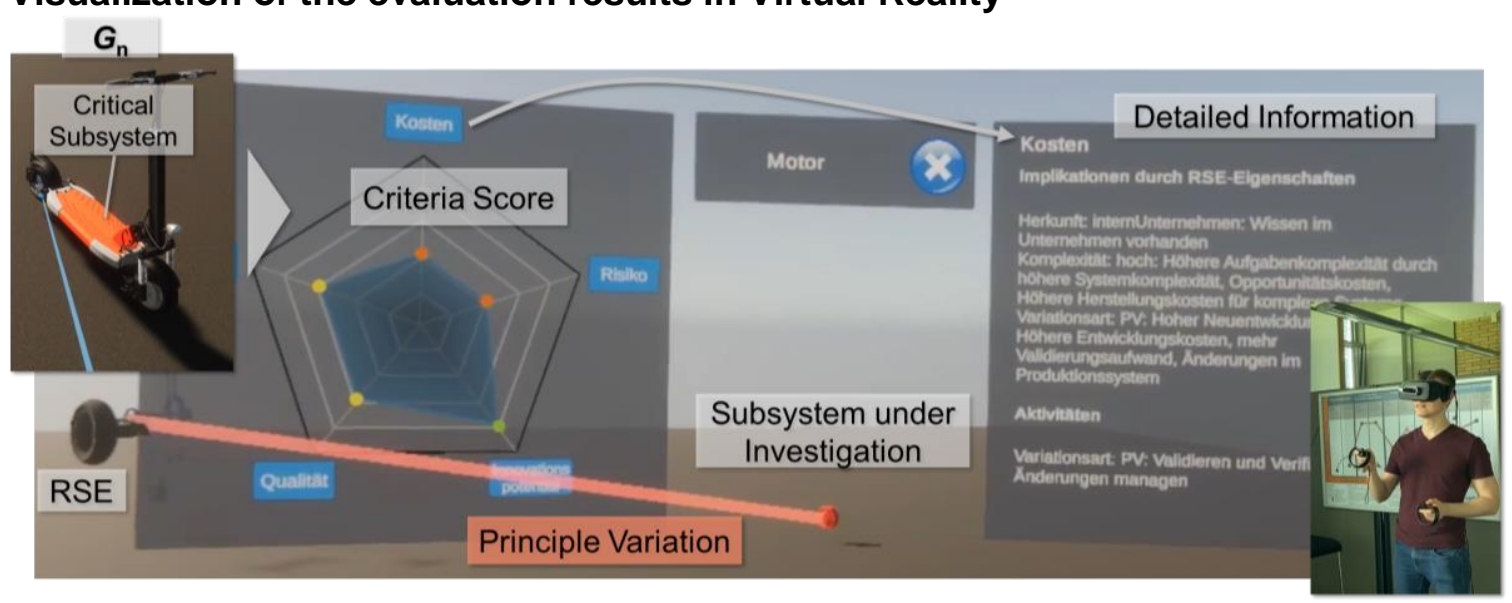

Figure 6: Visualization of the evaluation results for the mock-up scenario

For the visualization of the results, a general overview is first provided. For this purpose, the 3D model of the $G_{\mathrm{n}}$ with its subsystems (SubSys) and the $R_{\mathrm{n}}$ with its $R S E$ are presented. Subsystems of the $G_{\mathrm{n}}$, where the evaluation for a criterion is negative or very negative, are marked red (see Figure 6 top left corner). In this way, the critical systems can be seen at a glance. In VR, zooming in on subsystems of interest is achieved by moving towards the object by walking or flying freely through virtual space. This allows the user to move freely and intuitively on or even within the system. By using the virtual 
laser pointer, the user selects the subsystems for which he would like more detailed information. The detail view shows the colour-coded variation relationship and three combined panels, which provide information about the score of the criteria and which impact factors lead to it (Figure 6).

A red beam from the subsystem under investigation (Hub-Motor of the e-scooter)) to the RSE (middle-motor of an e-bike) indicates the principle variation. The evaluation results of the evaluation criteria are shown in a spider diagram (left panel). Detailed information on the individual criterion (right panel), what impact variables it gets effected by and what upcoming development activities could be necessary, is listed by clicking on the criteria in the left panel.

\section{CONCLUSION}

This contribution proposes a data model combined with a mathematical model to store knowledge about the impact of characteristics of reference system elements and variations on evaluation criteria such as common development targets and to make it applicable for supporting decision making in product development. The already existing knowledge base on these impacts in research on PGE Product Generation Engineering was built up with a literature analysis, in which also gaps regarding the impact on activities, quality and sustainability could be identified.

With the development of a VR visualization application, it could be shown that the data model building upon the model of PGE - Product Generation Engineering is very well applicable and useful for implementation in technical information systems. The clear definition of the reference system elements, their corresponding subsystems and the variation relation contribute to this, as this facilitates object-oriented programming. Also, the Entity-Relationship modelling approach combined with an extendable mathematical model enables the easy implementation of data structures and algorithms for the evaluation of the impact on the criteria.

\section{OUTLOOK}

Regarding the impacts of reference system elements and their characteristics on the $G_{\mathrm{n}}$, important relationships have already been identified in this work. However, the reference system and its elements may have even more far-reaching effects on the development process. The model for impact factors and criteria presented in section 5 can form the basis for further quantitative investigations on both the impact factor and the criteria side. The criteria and impact factors already identified should also be further explored and validated. In particular, activities that follow on from reference system elements with certain characteristics are relevant for decision-making and the planning of product development processes and can be collected with further studies. The simplifications made for modelling should also be gradually removed in the next iterations. The findings of this work can be used to integrate the knowledge from PGE research into other digital and virtual methods.

\section{REFERENCES}

Albers, A., Bursac, N. and Rapp, S. (2017a), "PGE - Produktgenerationsentwicklung am Beispiel des Zweimassenschwungrads", Forschung im Ingenieurwesen, Vol. 81 No. 1, pp. 13-31.

Albers, A., Bursac, N. and Wintergerst, E. (2015), "Product Generation Development - Importance and Challenges from a Design Research Perspective”, International Conference on Theoretical Mechanics and Applied Mechanics (TMAM), Vienna, Austria, March 15-17.

Albers, A., Heimicke, J., Walter, B., Basedow, G.N., Reiß, N., Heitger, N., Ott, S. and Bursac, N. (2018), "Product Profiles: Modelling customer benefits as a foundation to bring inventions to innovations", Procedia CIRP, Vol. 70, pp. 253-258.

Albers, A., Rapp, S., Birk, C. and Bursac, N. (2017b), "Die Frühe Phase der PGE -

Produktgenerationsentwicklung”, in Binz, H., Bertsche, B., Bauer, W., Spath, D. and Roth, D. (Eds.), 4. Stuttgarter Symposium für Produktentwicklung SSP 2017, June 28-29, Stuttgart, Germany, Fraunhofer, Stuttgart, pp. 345-354.

Albers, A., Rapp, S., Fahl, J., Hirschter, T., Revfi, S., Schulz, M., Stürmlinger, T. and Spadinger, M. (2020), "Proposing a generalized Description of Variations in different types of Systems by the Model of PGE Product Generation Engineering”, Proceedings of the Design Society: DESIGN Conference, Vol. 1, pp. 2235-2244.

Albers, A., Rapp, S., Peglow, N., Stürmlinger, T., Heimicke, J., Wattenberg, F. and Wessels, H. (2019a), "Variations as Activity Patterns: A Basis for Project Planning in PGE - Product Generation Engineering", Procedia 29th CIRP Design Conference, No. 84, pp. 966-972. 
Albers, A., Rapp, S., Spadinger, M., Richter, T., Birk, C., Marthaler, F., Heimicke, J., Kurtz, V. and Wessels, H. (2019b), "The Reference System in the Model of PGE: Proposing a Generalized Description of Reference Products and their Interrelations", International Conference on Engineering Design (ICED19), Delft, Netherlands, August 5-8, Design Society, Glasgow, pp. 1693-1702.

Albers, A., Bursac, N., Urbanec, J., Lüdcke, R. and Rachenkova, G. (2014), "Knowledge Management in Product Generation Development - an empirical study”, 25th Symposium Design for X (DFX) 2014, Bamberg, Germany, October 1-2, TuTech Verlag, Berlin, pp. 13-24.

Alblas, A. and Jayaram, J. (2015), "Design resilience in the fuzzy front end (FFE) context: an empirical examination", International Journal of Production Research, Vol. 53 No. 22, pp. 6820-6838.

Bailom, F., Hinterhuber, H.H., Matzler, K. and Sauerwein, E. (1996), "Das Kano-Modell der Kundenzufriedenheit”, Marketing ZFP, Vol. 18 No. 2, pp. 117-126.

Breiing, A. and Knosala, R. (1997), Bewerten technischer Systeme: Theoretische und methodische Grundlagen bewertungstechnischer Entscheidungshilfen, Springer Berlin Heidelberg, Berlin, Heidelberg, Germany.

Card, S.K., Mackinlay, J.D. and Shneiderman, B. (Eds.) (1999), Readings in information visualization: Using vision to think, The Morgan Kaufmann series in interactive technologies, Morgan Kaufmann, San Francisco, USA.

Chen, P.P.-S. (1976), “The entity-relationship model---toward a unified view of data", ACM Transactions on Database Systems, Vol. 1 No. 1, pp. 9-36.

Cross, N. (2008), Engineering design methods: Strategies for product design, Wiley, Chichester, England.

Dörner, R., Broll, W., Grimm, P. and Jung, B. (2019), Virtual und Augmented Reality (VR/AR), Springer Berlin Heidelberg, Berlin, Heidelberg, Germany.

Ehrlenspiel, K., Kiewert, A., Lindemann, U. and Mörtl, M. (2014), Kostengünstig Entwickeln und Konstruieren, Springer Berlin Heidelberg, Berlin, Heidelberg, Germany.

Ehrlenspiel, K. and Meerkamm, H. (2017), Integrierte Produktentwicklung: Denkabläufe, Methodeneinsatz, Zusammenarbeit, Carl Hanser Verlag GmbH \& Co. KG, München, Germany.

Gadatsch, A. (2019), Datenmodellierung: Einführung in die Entity-Relationship-Modellierung und das Relationenmodell, Springer Fachmedien Wiesbaden, Wiesbaden, Germany.

Hatchuel, A. and Weil, B. (2003), "A new approach of innovative design: an introduction to CK theory", International Conference on Engineering Design (ICED 14), Stockholm, Sweden, August 19 - 21, Design Society, Glasgow.

Heismann, R. and Maul, L. (2012), "Mit systematischem Innovationsmanagement zum Erfolg”, in Ili, S. and Albers, A. (Eds.), Innovation Excellence: Wie Unternehmen ihre Innovationsfähigkeit systematisch steigern, Symposion Publishing, Düsseldorf, Germany, pp. 39-61.

Hubka, V. (1984), Theorie Technischer Systeme: Grundlagen einer wissenschaftlichen Konstruktionslehre, Springer Berlin Heidelberg, Berlin, Heidelberg, Germany.

North, K. (2016), Wissensorientierte Unternehmensführung: Wissensmanagement gestalten, Springer Gabler, Wiesbaden, Germany.

Olesen, J., Wenzel, H., Hein, L. and Andreasen, M.M. (1996), Design for Environment, Ministry for Environment and Energy, Environmental Protection Agency.

Reinemann, J., Hirschter, T., Mandel, C., Heimicke, J. and Albers, A. (2018), "Methodische Unterstützung zur Produktvalidierung in AR-Umgebungen in der Frühen Phase der PGE - Produktgenerationsentwicklung", 29. DfX-Symposium, Tutzing, Germany, 25.-26. September, pp. 307-320.

Ropohl, G. (2009), Allgemeine Technologie eine Systemtheorie der Technik, KIT Scientific Publishing, Karlsruhe.

Schumpeter, J.A. (1934), The theory of economic development: An inquiry into profits, capital, credit, interest, and the business cycle, Harvard economic studies, vol. XLVI, Harvard University Press, Cambridge, USA.

Shahin, T.M.M., Andrews, P.T.J. and Sivaloganathan, S. (1999), “A design reuse system”, Proceedings of the Institution of Mechanical Engineers, Part B: Journal of Engineering Manufacture, Vol. 213 No. 6, pp. 621627.

Shneiderman, B. (1996), "The eyes have it: a task by data type taxonomy for information visualizations", IEEE Symposium on Visual Languages, Boulder, CO, USA, pp. 336-343.

Takeuchi, H. and Nonaka, I. (2012), Die Organisation des Wissens: Wie japanische Unternehmen eine brachliegende Ressource nutzbar machen, Business 2012, 2. Aufl., Campus Verlag, Frankfurt am Main.

Times, T.S. (2020), James Dyson interview: how I blew £500m on electric car to rival Tesla. [online] The Sunday Times, 16 May. Available at: https://www.thetimes.co.uk/article/james-dyson-interview-electriccar-tesla-

tzls09t5m?wgu=270525_54264_1589789181059_309d535209\&wgexpiry=1597565181\&utm_source=plani t\&utm_medium=affiliate\&utm_content=22278 (accessed 28 November 2020).

Ware, C. (2013), Information visualization: Perception for design, Elsevier/MK, Amsterdam, Boston.

Wißler, F.E. (2006), Ein Verfahren zur Bewertung technischer Risiken in der Phase der Entwicklung komplexer Serienprodukte, Dr. Ing Thesis, Universität Stuttgart. 